\title{
Helicobacter pylori infection with iron deficiency anaemia and subnormal growth at puberty
}

\author{
Yon Ho Choe, Soon Ki Kim, Yun Chul Hong
}

\begin{abstract}
The purpose of this study was to determine whether Helicobacter pylori infection can contribute to growth deficit, especially in pubescent children who need large amounts of iron for growth. A structured questionnaire was sent to the parents of 532 healthy children aged 10 to 15 years (mean 12.9) to obtain demographic information on the parents and the environment. Of the 532 questionnaires sent out, 375 (70.5\%; 170 girls and 205 boys) were returned. After collecting blood samples from participants, haemoglobin, serum iron, total iron binding capacity, serum ferritin, and serum IgG antibodies to $H$ pylori were measured. The effects of risk factors such as $H$ pylori infection, iron deficiency anaemia, sex, socioeconomic status, type of house, and crowding index on growth were analysed using multiple regression analysis. Of $63 \mathrm{H}$ pylori positive children, $18(28.6 \%)$ were below the 25th centile values for height, compared with 63 of $312(20.2 \%) H$ pylori negative children. The prevalence rate of $H$ pylori infection was $15.5 \%$ (53 of 343) in children without iron deficiency anaemia and $31.3 \%$ (10 of 32$)$ in those affected. The relative risk of short stature was $2.2(95 \%$ confidence interval (CI), 1.0 to 4.8 ) for iron deficiency anaemia, and $1.4(95 \% \mathrm{CI}$, 0.8 to 2.4) for $H$ pylori infection. The mean height was significantly lower in the group having both $H$ pylori infection and iron deficiency anaemia. Therefore, $H$ pylori infection accompanied by iron deficiency anaemia, rather than $H$ pylori infection per se, might delay pubertal growth. (Arch Dis Child 2000;82:136-140)
\end{abstract}

Department of Pediatrics, Inha University Hospital, Inha University College of Medicine, 7-206, 3-Ga, Shinheung-Dong, Jung-Gu, Inchon 400-103, Korea

Y H Choe

S K Kim

Department of Preventive Medicine, Inha University College of Medicine Y C Hong

Correspondence to: Dr Choe

email: yhchoe@

dragon.inha.ac.kr

Accepted 13 October 1999
Several studies have investigated the effects of $H$ pylori infection on children's growth. A
French study showed that $H$ pylori was found in over half of the children being examined because of their short stature. ${ }^{6}$ Another European study revealed that $H$ pylori infection was associated with the subnormal growth of older girls only, at around the time of puberty. ${ }^{7} \mathrm{~A}$ recent study in Italy found that a reduction in height seen in older children aged 8.5 to 14 years was related to $H$ pylori infection. ${ }^{8}$ In this study, they suggest that $H$ pylori might be one of the environmental factors capable of affecting growth. The mechanism of this association has not been elucidated.

Recently, we conducted a double blinded, placebo controlled trial in older children with iron deficiency anaemia and a coexisting $H$ pylori infection. ${ }^{9}$ We found that $H$ pylori infection can contribute to iron deficiency anaemia, and that infection should be suspected when the iron deficiency anaemia is refractory to iron administration. We also proposed that treatment for iron deficiency anaemia coexistent with $H$ pylori infection should include $H$ pylori eradication. Iron requirements in adolescents are high, and much iron is needed to supply the high requirements for growth. ${ }^{10}$ Iron deficiency during this crucial period results in a reduction of longitudinal growth and weight gain. ${ }^{11}{ }^{12}$

The purpose of our study was to determine whether $H$ pylori infection can contribute to growth deficit, especially around the time of puberty, when children need large amounts of iron for growth.

\section{Methods}

SUBJECTS

We recruited 532 healthy children (285 boys and 247 girls) aged 10 to 15 years from the Pucheon anaemia study, which was launched in October 1996. The aim of the study was to investigate the prevalence of anaemia and the iron status of school children in Pucheon, a city near Seoul, Korea. The criteria for enrollment included: no history of severe diseases, no recent use of drugs such as antibiotics or antacids, and no use of remedies containing iron. Parents of subjects were informed about the study by letter. Of the 532 questionnaires sent out, 375 ( $70.5 \%$; 205 boys and 170 girls) were returned.

\section{QUESTIONNAIRE}

A structured questionnaire was sent to the children's parents, with the help of school teachers, to obtain parental information on: occupation; educational level; and environmental information, such as the type of house, number of rooms in the house, and number of 
persons living in the house. Informed consent was obtained from every parent before children were enrolled in our study.

LABORATORY ASSAYS

Blood samples of participants were obtained by venepuncture. After collecting the blood samples, various haematological studies were performed, which included the measurement of haemoglobin, serum iron, total iron binding capacity, and serum ferritin. Serum IgG antibodies to $H$ pylori were also measured. The haemoglobin concentration was measured using a Coulter S-PLUS IV (Coulter Electronics, Miami, Florida, USA). Serum was separated and stored at $-20^{\circ} \mathrm{C}$ for analysis of iron deficiency. Serum iron and total iron binding capacity were determined spectrophotometrically (Hitachi, Tokyo, Japan). Transferrin saturation was calculated by dividing the concentration of serum iron by the total iron binding capacity. The serum ferritin assay was performed using a radioimmunoassay kit (Ferritin-Iron II; Ramco Laboratories, Houston, Texas, USA). Serum IgG antibodies to $H$ pylori were measured using an enzyme linked immunosorbent assay (ELISA), the GAP test IgG kit (Bio-Rad Laboratories, Hercules, California, USA).

METHODS OF ANALYSIS

Iron deficiency anaemia was defined as a low serum ferritin concentration $(<12 \mathrm{ng} / \mathrm{ml})$, low transferrin saturation $(<15 \%)$, and a low haemoglobin concentration $(<120 \mathrm{~g} / \mathrm{l}) .^{13}$ Helicobacter pylori infection was defined as a positive ELISA result. Centile values of height and weight were obtained by using standard Korean children's height and weight charts. We used the 25th centile values for height or weight as the threshold values for subnormal growth. To identify risk factors affecting growth, we sorted the subjects into four groups, based on the presence or absence of $H$ pylori infection and iron deficiency anaemia, and which were defined as follows: (1) subjects having both iron deficiency anaemia and $H$ pylori infection (IDA+/Hp+; $\mathrm{n}=10)$; (2) subjects having iron deficiency anaemia only (IDA+/Hp-; $\mathrm{n}=22$ ); (3) subjects having $H$ pylori infection only (IDA-/Hp+; $\mathrm{n}=53$ ); and (4) subjects having neither iron deficiency anaemia nor $H$ pylori infection (IDA- $/ \mathrm{Hp}-$, $\mathrm{n}=290)$. The means and $95 \%$ confidence intervals (CI) of height and weight distributions were calculated, and statistical adjustment was made for age differences; the four groups were then compared. The statistical interaction between $H$ pylori infection and iron deficiency anaemia was also examined.

Sex, socioeconomic class, and household crowding were included as variables because it is known that they can affect the prevalence rate of $H$ pylori infection and iron deficiency anaemia. Categorisation of socioeconomic class was based on the parents' occupation and education by applying the Hollingshead index ${ }^{14}$ (table 1). Five educational levels and five occupational categories were used to identify socioeconomic classes. A score of 0 was given to the
Table 1 Educational and occupational levels of both parents used in forming the Hollingshead index of socioeconomic class

\begin{tabular}{llll}
\hline Education & Score & Occupation & Score \\
\hline No education & 0 & No occupation & 0 \\
Elementary school & 1 & Workman & 1 \\
Junior school & 2 & Blue collar worker & 2 \\
High school & 3 & White collar worker & 3 \\
University & 4 & Professional & 4 \\
\hline
\end{tabular}

Educational and occupational scores of parents:

$0-4, \mathrm{I}$

$5-8$, II

9-12, III

13-16, IV

lowest level of education and occupation and a score of 4 was given to the highest. Four socioeconomic classes were identified ranging from lowest (I) to highest (IV) on the basis of the sum of scores. Household crowding was shown by a crowding index: the number of persons living in the house divided by the number of rooms.

STATISTICAL ANALYSES

The $\chi^{2}$ test and the Mantel-Haenszel $\chi^{2}$ test were used to assess the association between the independent factors related to the prevalence of $H$ pylori infection and growth. The effects of risk factors such as $H$ pylori infection, iron deficiency anaemia, sex, socioeconomic status, type of house, and crowding index on growth were analysed by multiple logistic regression modelling. These models enabled the assessment of the relative importance of $H$ pylori infection and iron deficiency anaemia while controlling for the other risk factors.

We used ANOVA to calculate and compare the mean and $95 \%$ CI values for the height and weight distributions after adjustment for age. The interactive effect of $H$ pylori infection coupled with iron deficiency anaemia on growth was analysed by using the interaction term of $H$ pylori infection and iron deficiency anaemia. Unless stated otherwise, a $p$ value $\leqslant 0.05$ was taken to be significant. All statistical analyses were performed using SAS statistics software (version 6.12).

\section{Results}

The ages of participants ranged from 10 to 15 years (mean, 12.9 years). No differences were found in the demographic or physiological variables or the prevalences of $H$ pylori infection and iron deficiency anaemia between those who did and those who did not respond to the questionnaire.

Sixty three of 375 children $(16.8 \%)$ were infected with $H$ pylori. Iron deficiency anaemia was found in $8.5 \%$. Table 2 summarises the effects of independent variables on height and weight by univariate analyses. We found that 18 of $63(28.6 \%)$ of $H$ pylori positive children were below the 25th centile values for height, compared with 63 of 312 (20.2\%) of H pylori negative children. However, this difference was not significant $(p=0.14)$. Significant differences in height and weight were found between those children with and without iron deficiency anaemia ( $p=0.006$ and 0.007 , respectively). 
Table 2 The effects of independent variables on growth by univariate analyses

\begin{tabular}{|c|c|c|c|c|}
\hline Category & $\begin{array}{l}\text { Below the } 25 \text { th } \\
\text { centile values for } \\
\text { height (\%) }\end{array}$ & $p$ Value & $\begin{array}{l}\text { Below the } 25 \text { th } \\
\text { centile values for } \\
\text { weight (\%) }\end{array}$ & $p$ Value \\
\hline \multicolumn{5}{|c|}{ Helicobacter pylori infection } \\
\hline Negative & 20.2 & & 26.9 & \\
\hline Positive & 28.6 & 0.14 & 25.4 & 0.803 \\
\hline \multicolumn{5}{|c|}{ Iron deficiency anaemia } \\
\hline Negative & 19.8 & & 24.8 & \\
\hline Positive & 40.6 & 0.006 & 46.9 & 0.007 \\
\hline \multicolumn{5}{|l|}{ Sex } \\
\hline Male & 19.5 & & 23.4 & \\
\hline Female & 24.1 & 0.281 & 30.6 & 0.118 \\
\hline \multicolumn{5}{|c|}{ Socioeconomic class } \\
\hline $\mathrm{I}+\mathrm{II}$ & 20.9 & & 24.4 & \\
\hline III & 22.1 & & 28.7 & \\
\hline IV & 18.8 & 0.927 & 12.5 & 0.930 \\
\hline \multicolumn{5}{|c|}{ Housing tenure } \\
\hline Owned & 22.1 & & 26.8 & \\
\hline Rented & 20.7 & 0.748 & 26.4 & 0.936 \\
\hline \multicolumn{5}{|c|}{ Crowding index } \\
\hline$<1.5$ & 19.6 & & 27.0 & \\
\hline$\geqslant 1.5$ & 23.1 & 0.417 & 26.4 & 0.900 \\
\hline
\end{tabular}

The prevalence rate of $H$ pylori infection was $15.5 \%$ (53 of 343 ) in children without iron deficiency anaemia and $31.3 \%$ (10 of 32 ) in those affected $(p=0.022)$. The presence of iron deficiency anaemia was found to be significant by univariate analysis, but no such relation was found between $H$ pylori infection and growth. Helicobacter pylori infection was also included in the multiple logistic regression model because there is a known relation between $H$ pylori infection and iron deficiency anaemia. Table 3 shows the relative risks for height and weight in relation to $H$ pylori infection and iron deficiency anaemia. In the logistic regression model, the relative risk of height below the 25 th centile values was 2.2 (95\% CI, 1.0 to 4.8 ) for the iron deficiency anaemia group, and 1.4 (95\% CI, 0.8 to 2.4 ) for the $H$ pylor $i$ infected group. The relative risk of weight below the 25 th centile values was 2.1 (95\% CI, 1.0 to 4.6 ) for iron deficiency anaemia, and 0.7 (95\% CI, 0.4 to 1.3 ) for $H$ pylori infection.

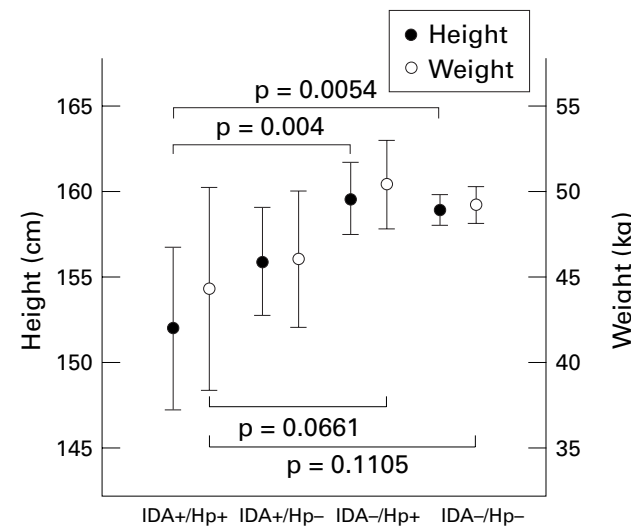

Figure 1 Comparison of the means of height and weight among the four groups. IDA+/Hp+, subjects with both iron deficiency anaemia and Helicobacter pylori infection $(n=10) ; I D A+/ H p-$, subjects with iron deficiency anaemia only $(n=22) ; I D A-/ H p+$, subjects with $H$ pylori infection only ( $n=53)$; and IDA-/Hp-, subjects with neither iron deficiency anaemia nor $H$ pylori infection $(n=290)$. Ranges are $95 \%$ confidence intervals. The means of height and weight decreased in the group with both $H$ pylori infection and iron deficiency anaemia ( $p=0.0104$ for height and 0.1252 for weight).

Table 4 shows the means of the heights and weights obtained after adjustment for age in the four groups (IDA $+/ \mathrm{Hp}+, \mathrm{IDA}+/ \mathrm{Hp}-$, IDA-/ $\mathrm{Hp}+$, and IDA-/Hp-). The mean height of subjects decreased significantly in the group having both $H$ pylori infection and iron deficiency anaemia $(\mathrm{p}=0.0104$; fig 1$)$. No significant interaction was found between $\mathrm{H}$ pylori infection and iron deficiency anaemia in terms of growth $(p=0.2247)$.

\section{Discussion}

Our data show that although $H$ pylori infection seemed to affect growth when the population was analysed solely on the basis of infection, this is a result of the association between $H$ pylori infection and iron deficiency anaemia. It

Table 3 The results of logistic regression analysis of variables that are significant in the univariate analysis and their association with height and weight

\begin{tabular}{|c|c|c|c|c|c|c|c|c|}
\hline & \multicolumn{4}{|l|}{ Height } & \multicolumn{4}{|l|}{ Weight } \\
\hline & $\begin{array}{l}\text { Number } \\
\text { (\% positive)* }\end{array}$ & $R R$ & $95 \% C I$ & $p$ Value & $\begin{array}{l}\text { Number } \\
\text { (\% positive)* }\end{array}$ & $R R$ & $95 \% C I$ & $p$ Value \\
\hline \multicolumn{9}{|c|}{ Helicobacter pylori infection } \\
\hline Negative & $63(20.2)$ & & & & $84(26.9)$ & & & \\
\hline Positive & $18(28.6)$ & 1.4 & $0.8-2.4$ & 0.34 & $16(25.4)$ & 0.7 & $0.4-1.3$ & 0.37 \\
\hline \multicolumn{9}{|c|}{ Iron deficiency anaemia } \\
\hline Negative & $68(19.8)$ & & & & $85(28.4)$ & & & \\
\hline Positive & $13(40.6)$ & 2.2 & $1.0-4.8$ & 0.05 & $15(46.9)$ & 2.1 & $1.0-4.6$ & 0.05 \\
\hline
\end{tabular}

*Percentage of children below the 25 th centile values for height and weight.

$\mathrm{CI}$, confidence interval; RR, relative risk.

Table 4 Adjusted means (95\% confidence intervals) of height and weight for age

\begin{tabular}{|c|c|c|c|c|c|c|c|c|c|}
\hline & \multicolumn{3}{|l|}{ Boys } & \multicolumn{3}{|l|}{ Girls } & \multicolumn{3}{|l|}{ Total } \\
\hline & Height $^{\star}$ & Weight $t^{\star *}$ & $n$ & Height $^{\star \star \star}$ & Weight & $n$ & Height $\neq$ & Weight & $n$ \\
\hline $\mathrm{IDA}+/ \mathrm{Hp}+$ & $\begin{array}{l}152.9 \\
(144.4 \text { to } 161.3)\end{array}$ & $\begin{array}{l}41.1 \\
(29.0 \text { to } 53.1)\end{array}$ & 3 & $\begin{array}{l}151.8 \\
(146.9 \text { to } 156.6)\end{array}$ & $\begin{array}{l}45.8 \\
(40.3 \text { to } 51.4)\end{array}$ & 7 & $\begin{array}{l}152.0 \\
(147.2 \text { to } 156.7)\end{array}$ & $\begin{array}{l}44.3 \\
(38.3 \text { to } 50.3)\end{array}$ & 10 \\
\hline $\mathrm{IDA}+/ \mathrm{Hp}-$ & $\begin{array}{l}159.2 \\
(154.1 \text { to } 164.3)\end{array}$ & $\begin{array}{l}46.1 \\
(38.9 \text { to } 53.4 \text { ) }\end{array}$ & 8 & $\begin{array}{l}155.0 \\
(151.5 \text { to } 158.4)\end{array}$ & $\begin{array}{l}46.7 \\
(42.7 \text { to } 50.7)\end{array}$ & 14 & $\begin{array}{l}155.9 \\
(152.7 \text { to } 159.1)\end{array}$ & $\begin{array}{l}46.0 \\
(42.0 \text { to } 50.0)\end{array}$ & 22 \\
\hline IDA-/Hp+ & $\begin{array}{l}162.8 \\
(160.3 \text { to } 165.4)\end{array}$ & $\begin{array}{l}53.4 \\
(49.8 \text { to } 57.0)\end{array}$ & 32 & $\begin{array}{l}154.6 \\
\text { (151.8 to } 157.4)\end{array}$ & $\begin{array}{l}45.7 \\
(42.6 \text { to } 48.9)\end{array}$ & 21 & $\begin{array}{l}159.6 \\
(157.5 \text { to } 161.7)\end{array}$ & $\begin{array}{l}50.4 \\
(47.8 \text { to } 53.0)\end{array}$ & 53 \\
\hline IDA-/Hp- & $\begin{array}{l}161.4 \\
(160.3 \text { to } 162.5)\end{array}$ & $\begin{array}{l}51.4 \\
(49.8 \text { to } 53.0)\end{array}$ & 161 & $\begin{array}{l}155.6 \\
\text { (154.4 to } 156.7)\end{array}$ & $\begin{array}{l}46.4 \\
(45.1 \text { to } 47.7 \text { ) }\end{array}$ & 129 & $\begin{array}{l}158.9 \\
(158.0 \text { to } 159.8)\end{array}$ & $\begin{array}{l}49.2 \\
\text { ( } 48.1 \text { to } 50.3 \text { ) }\end{array}$ & 290 \\
\hline
\end{tabular}

${ }^{\star} \mathrm{p}=0.1159 ;{ }^{\star \star} \mathrm{p}=0.1116 ;{ }^{\star \star \star} \mathrm{p}=0.4715 ; \mathrm{tp}=0.9752 ; \neq \mathrm{p}=0.0104 ; \mathrm{q}=0.1252$

IDA+/Hp+, subjects with both iron deficiency anaemia and Helicobacter pylori infection; IDA+/Hp-, subjects with iron deficiency anaemia only; IDA-/Hp+, subjects with $H$ pylori infection only; IDA-/Hp-, subjects without iron deficiency anaemia or $H$ pylori infection. 
is unlikely that $H$ pylori infection alone is directly associated with the reduced growth of children, as some other studies have suggested. ${ }^{78}$ Perri et al proposed four mechanisms by which $H$ pylori infection might lead to short stature. ${ }^{8}$ First, that it could cause dyspeptic symptoms. Second, that the infection could result in a low energy intake and malnutrition. Third, that a long standing infection induces low grade chronic gastric inflammation and the release of cytokines that could affect growth. Finally, that $H$ pylori might be associated with poor socioeconomic background, malnutrition, and exposure to other chronic diseases, which could affect growth. However, our findings reveal that $H$ pylori infection coupled with coexisting iron deficiency anaemia is associated with subnormal growth at puberty, which is particularly associated with height.

The diagnosis of $H$ pylori infection was assessed only by means of specific serum IgG antibodies. This is based on our experience of various tests used to diagnose $H$ pylori infection in Korean children. ${ }^{15}$ In our study, serological examination using the GAP test IgG kit showed a sensitivity of $94.9 \%$ and a specificity of $92.4 \%$ in Korean children. Hence, we used this test for the diagnosis of $H$ pylori infection, although our case was somewhat weakened by the fact that $H$ pylori was identified by serology only.

In our recent study, we found that $H$ pylori infection contributed to iron deficiency anaemia, and that infection should be suspected when iron deficiency anaemia is refractory to iron administration. ${ }^{9}$ Treatment of $H$ pylori infection was associated with a more rapid response to oral iron treatment than the use of iron alone, and it led to an enhanced iron absorption even in those who did not receive oral iron supplementation. We hypothesised that iron deficiency anaemia coupled with $H$ pylori infection occurs most frequently in rapidly growing pubescent children. Adolescents are particularly susceptible to iron deficiency because of the high amounts of iron needed to sustain their growth, dietary deficiency, and menstrual blood loss in girls. ${ }^{10}$ Infection with $H$ pylori might affect iron absorption metabolism in the stomach and exacerbate the iron deficit in children whose iron is supplied marginally, with anaemia ensuing promptly. Therefore, when adolescents have iron deficiency anaemia, it is recommended that they should be evaluated for $H$ pylori infection. If they are found to have both, the iron deficiency anaemia should be treated by the eradication of $H$ pylori along with iron supplementation. It is hypothesised that when children who have been suffering from chronic $H$ pylori infection are affected with iron deficiency anaemia, especially during adolescence, their growth can be affected. Although the mechanisms by which $H$ pylori infection might lead to iron deficiency anaemia are still unclear, a recent study ruled out gastrointestinal bleeding or iron malabsorption and suggested that $H$ pylori gastritis could act as a sequestering focus for iron. ${ }^{16}$
We found $H$ pylori infection in 53 of 343 $(15.5 \%)$ children without iron deficiency anaemia and in 10 of $32(31.3 \%)$ affected children $(\mathrm{p}=0.022)$. Of $63 \mathrm{H}$ pylori positive children, $18(28.6 \%)$ were below the 25 th centile values for height, compared with 63 of $312(20.2 \%) H$ pylori negative children. Although this difference seemed to suggest that $H$ pylori infection could affect growth, it was not significant. After conducting logistic regression analysis, iron deficiency anaemia was still significantly associated with subnormal growth. The data from the analysis showed that iron deficiency anaemia had a significant effect on subnormal growth, rather than $H$ pylori infection, which contradicts previous reports. ${ }^{78}$

When the subjects were divided into four groups, a significant decrease in the mean height of subjects in the group with both $H$ pylori infection and iron deficiency anaemia was found. The data for boys and girls were analysed separately but no significant difference could be found, although it seems probable that such differences exist, particularly in terms of the height and weight of boys (table 4). We believe that this difference was not significant because the number in the IDA $+/ \mathrm{Hp}+$ group was too small for accurate analysis: three boys and seven girls.

We looked for an interaction between $\mathrm{H}$ pylori infection and iron deficiency anaemia but failed to identify any such interaction that influenced growth. In spite of the lack of an interaction, growth delay was identified in the group having $H$ pylori infection accompanied by iron deficiency anaemia, and our study shows that iron deficiency anaemia is an independent risk factor. In addition, there is evidence that $H$ pylori infection contributes to iron deficiency anaemia. ${ }^{9}$ Therefore, we believe that both $H$ pylori infection and iron deficiency anaemia might contribute to subnormal growth.

We conclude that $H$ pylori infection accompanied by iron deficiency anaemia, rather than $H$ pylori infection per se, might delay pubertal growth. When older children with reduced pubertal growth are found to be infected with $H$ pylori, iron deficiency anaemia can be considered to be a cause of the growth deficit. Likewise, when they are found to be affected with iron deficiency anaemia, they should be evaluated for $H$ pylori infection. If iron deficiency anaemia related to $H$ pylori infection is causally associated with growth delay in adolescents, eradication of $H$ pylori along with iron supplementation might be helpful in the treatment of children with pubertal growth delay and $H$ pylori infection.

\footnotetext{
We thank MY Seo and MY Kim for their valuable contribution to this work.

1 Megraud F, Brassens RMP, Denis F, Belbouri A, Hoa DQ Seroepidemiology of Campylobacter pylori infection in various populations. F Clin Microbiol 1989;27:1870-3.

2 Parsonnet J, Blaser MJ, Perez PG, Hargrett-Bean N, Tauxe RV. Symptoms and risk factors of Helicobacter pylori RV. Symptoms and risk factors of Helicobacter pylori infection in a cohort of epidemiologists. Gastroenterology Hill ID,

3 Hill ID, Sinclair-Smith C, Lastovica AJ, Bowie MD, Emms M. Transient protein losing enteropathy associated with acute gastritis and Campylobacter pylori. Arch Dis Child 1987;62:1215-19.
} 
4 Sullivan PB, Thomas JE, Wight DGD, et al. Helicobacter pylori in Gambian children with chronic diarrhoea and malnutrition. Arch Dis Child 1990;6

5 Dufour C, Brisigotti M, Fabretti G, Luxardo P, Mori PG Barabino A. Helicobacter pylori gastric infection and sideropenic refractory anemia. F Pediatr Gastroenterol Nutr 1993;17:225-7.

6 Raymond J, Bergert M, Benhamou H, Mensah K, Dupont C. A 2 -year study of Helicobacter pylori in children. $\mathcal{F}$ Clin Microbiol 1994;32:461-3.

7 Patel P, Mendall MA, Khulusi S, Northfield TC, Strachan DP. Helicobacter pylori infection in childhood: risk factor and effect on growth. BMF 1994;309:1119-23.

8 Perri F, Pastore M, Leandro G, et al. Helicobacter pylori infection and growth delay in older children. Arch Dis Child 1997;77:46-9.

9 Choe YH, Kim SK, Son BK, Lee DH, Hong YC, Pai SH. Randomized placebo-controlled trial of Helicobacter pylori eradication for iron-deficiency anemia in preadolescent eradication for iron-deficiency anemia in preadolesc
children and adolescents. Helicobacter 1999;4:135-9.

10 Hallberg L, Hulten L, Lindstedt G, et al. Prevalence of ironde- ficiency in Swedish adolescents. Pediatr Res 1993;34:680-7.

11 Sanstead HH, Carter JR, House FR, McConnell F, Horton $K B$, Vander Zwag R. Nutritional deficiencies in disadvanaged preschool children. Their relationship to mental development. Am f Dis Child 1971;121:455-63.

12 Chwang LC, Soemantri AG, Pollitt E. Iron supplementation and physical growth of rural Indonesian children. Am $\mathcal{F}$ Clin Nutr 1988;47:496-501.

13 Looker AC, Dallman PR, Carroll MD, Gunter EW, Johnson CL. Prevalence of iron deficiency in the United States. FAMA 1997;277:973-6.

14 Hollingshead A. Two factor index of social position. New Haven, USA: Yale University Press, 1957

15 Sim JG, Kim EC, Seo JK. The role of serology in the diagnosis of $\mathrm{H}$. pylori infection in children. Clin Pediatr 1995;34:458-62.

16 Barabino A, Dufour C, Marino CE, Claudiani F, De Alessandri A. Unexplained refractory iron-deficiency anechildren: further clinical evidence. 7 Pediatr Gastroenterol Nutr 1999;28:116-19.

\section{Periodic fever syndrome}

Periodic fever may be a challenging diagnostic problem and cause much anxiety. A relatively benign but extremely persistent form was described in Tennessee in 1987 and later given the acronym PFAPA (periodic fever, aphthous stomatitis, pharyngitis, and cervical adenitis). Now two reports in the fournal of Pediatrics have described 94 cases in America and 28 in Israel (Kenneth T Thomas and colleagues, 1999;135:15-21. Shai Padeh and colleagues, Ibid: 98-101. See also editorial by Sarah S Long, Ibid: 1-5).

The condition usually affects preschool children with a slight preponderance of boys. A striking feature is regular periodicity with episodes lasting three to six days and recurring every four or five weeks for years. In the two series some $30-40 \%$ of the children followed up had stopped having attacks and the mean total duration of the illness in those children was 4.5 years in America and 8 years in Israel. Aphthous stomatitis, pharyngitis, and cervical lymphadenopathy are each present in some $70-90 \%$ of cases. Another characteristic feature is that the children are usually relatively well during episodes and completely well between them, with normal growth and development and no long term sequelae. Apart from mild leucocytosis and mildly raised erythrocyte sedimentation rates during episodes there are no characteristic laboratory findings. Fever usually resolved rapidly after one or two doses of prednisone or prednisolone but this was followed by increased attack frequency in some. In the American series 11 patients had tonsillectomy and the episodes stopped after operation in seven of them.

The cause is unknown. The pros and cons of infection and "immune dysregulation" are discussed in the editorial.

ARCHIVIST 